\title{
Analysis of Factors Influencing the Cultivation of Physical Exercise Habits of College Students in Tianjin
}

\author{
Zhao Huibo \\ Tianjin Agricultural University, Department of Physical Education \\ Tianjin 300384, China
}

\begin{abstract}
It is an important task for college sports to cultivate college students' physical exercise habits and lay a solid foundation for their lifelong sports. The article discusses the definition of physical exercise habits, the psychological analysis of the formation of exercise habits, and discusses the factors affecting the formation of physical exercise habits. Starting from cultivating students' interest, and strengthening the organization and management of extracurricular physical exercise in the school management system so as to provide students with the necessary institutional guarantees for scientific physical exercise ability and good physical exercise habits; and it is necessary to strengthen the necessary sports facilities and venue equipment, provide a suitable environment for students' physical exercise, and implement the training of college students' physical exercise habits from various aspects.
\end{abstract}

\section{Keywords-Tianjin; College Student; Physical Exercise}

\section{INTRODUCTION}

The motivation of college students participating in extracurricular physical exercise in Tianjin is diversified. Enhancing physical fitness, recreational entertainment and relieving learning pressure are the main motives for male and female college students to participate in extracurricular physical exercise. The motivation of college students to participate in extracurricular physical exercise is not affected by the grade level. College students in natural sciences participate in extracurricular physical exercise to focus on relieving learning pressure and cultivating positive psychological quality. College students in social sciences participate in extracurricular physical exercise focusing on recreational entertainment and bodybuilding. Urban students from urban areas participate in extracurricular physical exercise focusing on recreational activities, improving motor skills and bodybuilding. College students in rural areas focus on relieving learning pressure and cultivating positive psychological qualities. There are differences in the motivations of college students participating in extracurricular physical exercise in different places of origin.

Tianjin college students participate in extracurricular physical exercise frequency every week, boys are significantly higher than girls, the difference is very significant. The difference between college students of different grades is very significant. The difference between college students in different disciplines is not significant. There are significant differences among college students from different places of origin. When Tianjin college students take part in extracurricular physical exercise for more than 30 minutes, the proportion of male students is significantly higher than that of female students. The difference is very significant. The difference between college students of different grades is very significant. The difference between college students in different disciplines is not significant. The difference between college students from different places of origin is not significant. Tianjin college students participate in extracurricular physical exercise programs. The most male students are basketball, table tennis and football. The most attended girls are badminton, running and aerobics. Boys like confrontational and technical sports, and girls focus on projects that are simple and functional. Basketball, badminton and running are among the top 3 students participating in extracurricular physical exercise programs in different grades, disciplines and students. Tianjin colleges and universities, college students, students of different grades, different disciplines and different students choose to participate in extracurricular physical exercise places, all in the same principle of convenience, economy and practicality. Male and female students are the same in the form of participation in extracurricular physical exercise. The first choice is to exercise with peers, followed by personal exercise. Class sports activities and club exercise forms are also the main choice for male and female college students. Seniors choose clubs to participate in extracurricular physical activity higher than class sports, which is different from the first three grades. College students from different disciplines and different students have the same form of extracurricular physical exercise. 


\section{MOTIVATION ANALYSIS OF COLLEGE STUDENTS IN TIANJIN CITY PARTICIPATING IN EXTRACURRICULAR PHYSICAL EXERCISES}

The motivations of college students and college students in Tianjin for the extracurricular physical exercise are the same in the top three. Both male and female college students ranked the first in terms of physical fitness; recreational entertainment ranked second; and learning pressure was ranked third. The essential characteristics and functions of physical exercise are to enhance physical fitness and improve health, which is the same for both men and women. British researchers have found that strengthening physical activity is not only good for your health, but also stimulates brain cell growth, memory and learning. With the development of society and the transformation of people's lifestyles, more and more people put health issues at the top of their values, and it is increasingly important to obtain health through sports. Therefore, regardless of male or female college students, taking part in extracurricular physical exercise is first and foremost in order to enhance physical fitness. Recreational entertainment is an important aspect of people's lifestyle. Physical exercise can enrich people's spare time and make them enjoy a good pastime. Through physical exercise, people can have a sense of pleasure and pleasure. It is also reasonable for male and female college students to participate in extracurricular physical exercise for the second place in recreational entertainment. Due to the pressure of college graduates' employment, college students try to participate in various training courses during their studies, and try to get more certificates, such as computer grade certificates and foreign language grade certificates, to enhance their competitiveness. Extracurricular physical exercise can delight the mind and body, relax the nervous brain, and meet the learning task with a healthy body and full spirit. It is indeed wise for male and female college students to choose extracurricular physical exercise to ease the pressure of learning. The motivation for boys to participate in extracurricular physical exercise is $4-6$, which is to improve their motor skills; to cultivate positive psychological quality and develop cooperation skills. The girls ranked 4-6 in the form of bodybuilding; cultivate positive psychological quality and improve motor skills. This sorting reflects the unique beauty of girls. Table 12 shows that the values of college students participating in extracurricular physical exercise in Tianjin are trend-oriented, oriented towards life, and diversified. The motivation of college students to participate in extracurricular physical exercise is closely related to their own needs. When arranging extracurricular physical exercise content, they should be fully considered in order to receive good results.

\section{THE MECHANISM AND PSYCHOLOGICAL ANALYSIS OF THE FORMATION OF PHYSICAL EXERCISE HABITS}

As a special social activity, sports has the functions of fitness, entertainment, education, politics and economy. Moreover, with the development of society, the connotation and extension of sports functions are constantly enhanced and expanded. Among them, fitness and entertainment are sports. The most essential function. Mainly manifested in, through appropriate physical exercise, can improve the sensitivity and flexibility of the central nervous system, enhance observation, memory and thinking, relieve nerve fatigue, thereby improving the function of the brain nervous system; The body's ability to exercise, enhance cardiovascular system function; Regular physical activity can enhance the body's immunity, prevent disease and rickets, delay aging, improve the quality of life; various forms of physical activity can entertain the body and mind, expand social interaction, ease life Stress, improve the quality of life; a certain form of physical activity can meet the individual's need to constantly surpass themselves and achieve personal value.

Motivation refers to the internal psychological process or internal driving force that causes and maintains individual activities and makes the activities face a certain target. [3] The motivation of physical exercise has a clear directivity and is the direct driving force for individuals to carry out conscious physical exercise. Its formation has many factors, which is not only the requirement for individuals to keep fit, to entertain the body and mind, to improve the quality of life and life, but also to the individual requirements of social development. Its formation is from generalization vagueness to differentiation specificity, from low level to The process of continuous development and change. First of all, the individual's needs are important factors in the formation of motivation for physical exercise. Through physical exercise, you can strengthen your body, enjoy your body and mind, aesthetic experience, spiritual catharsis, and temper your will. This instinct needs to promote exercise. Motivation is the most persistent and stable. Secondly, the influence of the living environment, the groups participating in sports around have a subtle influence on the individual, and they are delighted, excited, relished, or failed due to the victory of a sport. It' $s$ great for people to be embarrassed, lost, or appreciate the input of sports and self-indulgence. Attraction; Finally, the requirements of the school or the society for the individual. The social requirements for the individual are raised through the school and enter the society. Different occupations require people to have a healthy constitution, a good personality and a positive mental outlook. This need and the demands of society are constantly being met in sports activities and gradually form an internal driving force for certain activities.

The generation of exercise behavior is the first step in the formation of exercise habits. Exercise motivation is the internal driving force of exercise behavior. As long as there are external conditions for exercise behavior, exercise behavior naturally occurs. The key to the formation of exercise behavior to exercise habit is behavior The maintenance of this behavior is to achieve good results from the exercise process. The purpose of people participating in physical exercise is to meet the physiological, psychological and social needs, and when these needs are met, they form the motivation to continue to participate in exercise. Conversely, if the exercise does not achieve the intended purpose, it will weaken the motivation of exercise, and even give up continuing to exercise. Therefore, only the results of exercise can meet the individual's motivational goals, and exercise behavior can continue. 
After a certain behavior of a person is continuously strengthened, a fixed neural connection is established between the cerebral cortex and the cerebellum. As the result of the exercise behavior meets the needs of the subject's motivation, a good mood such as pleasure, satisfaction, and success is generated. Experience, stimulate the driving force of continuing exercise, and the repeated appearance of exercise behavior forms a fixed psychological set in psychology [4]. Exercise behavior improves people's quality of life, enriches life interest, expands interpersonal communication, and satisfies people. The desire to pursue a better life conforms to the harmonious development and progress of modern people and society, and prompts people to take physical exercise as an indispensable part of daily life and gradually form a habit.

\section{FACTORS AFFECTING THE DEVELOPMENT OF PHYSICAL EXERCISE HABITS}

Fitness and entertainment have been inextricably linked to sports activities since ancient times. However, the ancient fitness and entertainment purposes tend to be lower and simple. With the development of society, people gradually get rid of the constraints of low-level needs, and their self-awareness is gradually enhanced. The richness of sports activities and content constantly stimulates people's demand for fitness and entertainment. However, China is in an important period of social transformation, the interweaving of old and new concepts, and the pressure of social reality, making people rational about physical fitness and entertainment. Understanding the imbalance and instability, the contradiction between ideal and reality emerges. Modern young students are in the period of growth and development, active thinking, pursuing fashion, showing personality is their age characteristics. This makes them show their pursuit of fitness and entertainment. A certain degree of impetuousness, lack of rational understanding of fitness and entertainment, and a low level of spiritual pursuit. According to Wang Shizhe and other surveys on the health and physique concepts of 6,000 college students in five colleges and universities in Lanzhou area: 35. $6 \%$ of students do not know what is physical, 32. 3\% think that energy is healthy Even $7.0 \%$ of people think that it is health-free. The survey also found that most students think that they are healthy, do not need special exercise to improve, even if they want to exercise, they don't know how to exercise. Compared with the World Health Organization. Interpretation of the concept of health, and the results of surveys of college students' physical fitness, psychology, and social adaptability in recent years. It is not difficult to see that the comprehensive ability of modern college students' physical health knowledge, health awareness, and self-health ability is insufficient. Health is not high. This directly affects the level and level of students' current and future demand for physical fitness and recreation. Improving the level, breadth and level of students' sports needs is the key to developing their lifelong sports concept.

Contemporary college students have a strong sense of self. They are open-minded, open-minded, and strong-willed. Sports activities provide them with a platform for selfrealization. First, the need for self-realization is first manifested in personal pursuits, and sports activities are at the spiritual level. It contains a lot of aesthetic and fashion elements, such as sports stars, sportswear, sports, etc. They clearly show their personal pursuit style and show their personal value orientation for a certain kind of tendency mental activity or behavioral activities. Secondly, the need for self-realization is also manifested in self-expression. College students are the most self-expression group. In this era of advocating health, freedom and individuality, they will express their abilities and temperament through various ways and methods. 4. The difference in personality and superiority, sports activities are such a stage to show them fully.

Social communication as a way of social existence is a kind of interaction between people. The process of social interaction of college students is the process of mutual transformation of individual psychology and social psychology, that is, the process of social psychology individualization and individual psychosocialization. College students are in a period of immature sociality and urgent need for social recognition. Therefore, they have a stronger desire for social interaction. They become independent members of society through extensive social interaction and establishing their social status. This is their society. The basic needs of adaptability. Normal social interaction also makes them psychologically feel safe and belonging, and meet basic needs. Sports have activities, skills, cooperation, competitiveness, clustering and etiquette. , with a huge social education function, is an important way for students to psychosocialize

Studies have shown that there is no significant difference in the proportion of students with physical exercise habits between universities in mainland China and in mainland China, as well as in key universities. However, sports colleges and military academies are significantly more significant than other general institutions. Sexual differences. This shows that: the social requirements for students, that is, different occupational requirements, have an important impact on the development of students' physical exercise habits. In China's colleges and universities, in addition to sports, military, geology and other school-related majors In addition to higher requirements, most schools only have general requirements or no requirements. Professional needs through school education, internalization into individual student needs, further affecting changes in their behavioral habits. Therefore, improve social responsibility and self-conscious health awareness, and further improve The requirements of students are an important part of the transformation of school education thinking.

The school's sports grounds, equipment and facilities are the basic conditions for conducting sports activities. The school should provide students with adequate, safe, diverse and convenient sports venues and equipment. The main performance is, on the one hand, the number should be based on the school teacher. Secondly, the equipment and facilities of the sports ground should be equipped as far as possible to meet the needs of social development, and increase the content that students like, easy to accept, and easy to operate. Third, sports venues, equipment and facilities should ensure the basic needs of students. Sports safety, proper improvement of quality and grade, equipment and facilities should be regularly repaired and replenished. However, the lack of per capita possession of sports equipment is a common phenomenon in all types of schools in China. The main performances are as 
follows: Insufficient activity area and equipment. The Ministry of Education has clear regulations on the number of sports facilities per capita in colleges and universities across the country. At present, due to insufficient funds for the school to invest in sports facilities, it directly affects students' opportunities for physical exercise. In the investigation of factors affecting sports activities, the lack of physical activity venue equipment In fact, in recent years, due to the expansion of the enrollment scale of colleges and universities, this proportion has been reduced. Second, the physical activity facilities and equipment form is single, outdated. With the development of social economy, sports The number of activities and entertainment projects has gradually increased, and the form has gradually diversified. Students' requirements for the specifications of sports venues are constantly improving. Especially on the basis of improving physical quality, students have more prominent requirements for the entertainment of the project. Some traditional competitive High-demand items, such as: track and field, gymnastics, etc. are no longer liked by students. Third, the utilization rate of venue equipment is low. Due to the management and maintenance of the school's sports facilities, it requires a lot of manpower, material resources and financial resources. The lack of funds makes the existing equipment unable to perform its due function. Some sports venues and equipment are not used by students except for large-scale sports games. This further reduces the opportunities for students to exercise and also The formation of exercise habits has become a constraint.

The school sports culture system and sports culture atmosphere are the intangible factors that affect students' participation in physical exercise and the formation of physical exercise habits. School sports culture includes the sports concept, thoughts, speech, sports organization system, management system, and sports that are widely existed in schools. The physical form of the site, facilities, etc. Canada Stephen Licock said in my opinion in Oxford: What is really valuable to college students is the environment around him. Because the campus culture has orientation, education, radiation function, therefore, campus physical exercise The atmosphere has a subtle influence on improving students' sports culture literacy, establishing correct sports culture values, and forming good physical exercise habits. Psychological research shows that everyone has a herd mentality, and a good physical exercise atmosphere can make people form a mentality. Set the trend, and constantly internalize its own attitude in the subtle influence, so that its behavior is compatible with the surrounding environment. Therefore, strengthening the construction of campus sports culture plays an important role in promoting students' consciously forming physical exercise habits. Among them, the construction of school sports system is Forming sports The strong guarantee of the atmosphere, only the management department attaches great importance to it from top to bottom, establishes a sports management mechanism and organizational mechanism with unified integration, clear rights and responsibilities, and well-functioning, and carries out rich and colorful sports and cultural activities on this basis. Form a good sports culture atmosphere.

\section{CONCLUSION}

In general, the attitude of college students in Tianjin to participate in extracurricular physical exercise showed a positive agreement with the distribution, but with the increase of grades, it showed a trend of decreasing gradually. There was no difference between different disciplines and different places of origin (urban and rural areas). Significant difference $(p>0.05)$. In view of the current situation of extracurricular physical exercise in colleges and universities in Tianjin, all colleges and universities should further strengthen the functions of extracurricular physical exercise organization leadership departments, improve organization and management regulations, strengthen inter-school discussions and exchanges, learn from each other, and continuously promote the extracurricular activities of Tianjin ordinary college students. Physical exercise work.

\section{REFERENCES}

[1] Teng Chunyan, and so on. College students' extracurricular physical exercise investigation and its correlation with personality [J]. Zhejiang Sports Science, 2003, (4): 54-57.

[2] Zhao Yiping, Ma Li. Investigation and analysis of college students' participation in physical exercise [J]. Journal of Beijing Sport University, 2005, (7): 897-899.

[3] Li Guosheng, etc. Investigation and analysis of the current situation of college students' extracurricular physical exercise in Northwest China [J] Journal of Henan Institute of Science and Technology, 2006, (1): 110113.

[4] Pan Xiaobo, et al. Research on the current situation of college students' extracurricular physical exercise and related problems in Wuhan [J]. Sports Science and Technology Literature Report, 2007, (8): 99-103.

[5] Dong Jie, et al. Investigation and study on extracurricular physical exercise of undergraduates in ordinary universities in Northeast China [J]. Inner Mongolia Sports Science and Technology, 2007, (2): 86-87. 